\title{
O paradoxo constitucional brasileiro: direitos sociais sob tributação regressiva
}

\author{
The Brazilian constitutional paradox: \\ social rights cum regressive taxation
}

PEDRO FANDIÑO * CELIA LESSA KERSTENETZKY **;**

RESUMO: Este ensaio analisa o paradoxo constitucional brasileiro, de combinar expansão de direitos sociais com tributação regressiva, remetendo-o ao momento constituinte de 1987. O que esse momento revela é que a atual configuração regressiva do sistema tributário brasileiro, cuja origem se encontra na “Constituição cidadã” de 1988, não decorreu da ausência de uma proposta tecnicamente consistente de tributação progressiva - o que não permite descartar a hipótese política: "gastos sociais, sim, mas tributação progressiva, não”. PALAVRAS-CHAVE: Constituição de 1988; paradoxo da Constituição; tributação progressiva.

ABSTRACT: This essay reviews the Brazilian Constitutional paradox, the combination of expansion of social rights cum regressive taxation, by tracing it back to the Constitutionmaking process. This process shows the regressive feature of the Brazilian tax system, which originates in the so-called 1988 Citizen Constitution, not to derive from the absence of a thorough, technically consistent, proposal of progressive taxation. This reinforces the cogency of the political hypothesis: "social expenditure, no problem, provided the taxation is not progressive".

KEYWORDS: Brazilian 1988 Constitution; constitutional paradox; progressive taxation. JEL Classification: P16; H29.

\footnotetext{
" Doutorando no Programa de Pós-Graduação em Políticas Públicas, Estratégias e Desenvolvimento da Universidade Federal do Rio de Janeiro - PPED-UFRJ, Rio de Janeiro/RJ, Brasil. E-mail: fandinopedro@ gmail.com.

"* Professora Titular do Instituto de Economia da Universidade Federal do Rio de Janeiro - IE/UFRJ, Rio de Janeiro/RJ, Brasil. E-mail: celiakersten@gmail.com.

**** Celia Lessa Kerstenetzky é diretora do CEDE-UFRJ e pesquisadora do CNPq. Submetido: 19/Fevereiro/2018; Aprovado: 26/Julho/2018.
} 


\section{INTRODUÇÃO}

A Constituição Federal de 1988 (CF 1988) tem sido apontada como marco normativo para o desenvolvimento das políticas sociais no Brasil recente. Esse marco teria indicado caminhos para a consolidação de um estado do bem-estar social cujos princípios se aproximam de ideais universalistas. Tem sido menos notada, contudo, uma crítica inflexão: a partir de 1988, o sistema tributário brasileiro passou a assumir caráter crescentemente regressivo (Gobetti \& Orair, 2016; Kerstenetzky, 2017). A Constituição teria impelido o Estado a assumir funções abrangentes na garantia de direitos sociais e novos patamares de gastos, sem explicitamente ampará-los em arrecadação progressiva. Mais do que isso: criou mecanismos e formas de arrecadação que gradativamente viriam a comprometer a equidade do sistema tributário, como evidenciaremos neste artigo.

Enquanto se aventa a hipótese de que a perda de progressividade pós-CF 1988 estaria a refletir uma mudança de convenção fiscal no mundo pós-anos 1980 (Gobetti \& Orair, 2016), desse modo destacando a incidência de fatores exógenos, neste trabalho exploramos a hipótese alternativa de um acordo subjacente à Constituição (sugerida em Kerstenetzky, 2017), hipótese por assim dizer endógena, segundo a qual teriam sido amplamente acolhidas medidas favoráveis à expansão dos gastos sociais desde que seu financiamento não incidisse progressivamente sobre os mais ricos.

Tal hipótese é investigada de modo preliminar e indireto por meio da narração de eventos e circunstâncias que envolveram questões de justiça fiscal, durante e após o processo constituinte. Dois momentos são destacados: 1) o momento anterior à promulgação da Constituição, quando foram apresentadas à Assembleia Nacional Constituinte (ANC) propostas consistentes para a construção de um sistema tributário progressivo; e 2) os anos seguintes à promulgação da Carta, período em que foram regulamentadas decisões e introduzidas modificações que tornariam o sistema tributário cada vez menos progressivo.

Para a análise do primeiro momento, nos deteremos na proposta de reforma tributária, apresentada à ANC, por uma comissão de especialistas constituída com o intuito de subsidiar as discussões da Comissão do Sistema Tributário, Orçamento e Finanças. A proposta é analisada em detalhe no que respeita à tributação progressiva. Ademais, reconstituímos sua tramitação na ANC, desde a apresentação na referida Comissão até a fase final, na Comissão de Sistematização e posterior votação em plenário, quando se encerram os trabalhos constituintes. No segundo momento, documentamos as modificações sofridas pela tributação sobre a renda e o patrimônio, a partir da promulgação da Constituição, que redundariam em ulterior perda de progressividade no sistema tributário brasileiro.

Não se trata apenas de descrever os dois momentos, mas de propor uma interpretação na linha de continuidade, antes que de ruptura. A perda de prestígio da progressividade ao longo do processo constituinte resultou de um embate político e este segue sendo relevante para entender a regressividade que caracteriza o sistema tributário brasileiro até os dias de hoje. Um sistema peculiar, com baixo grau 
de progressividade no principal imposto progressivo e uma carga tributária que se apoia em tributos indiretos.

A seguir, apresentaremos o contexto e a construção da hipótese na segunda seção; o momento constituinte, as propostas da comissão de especialistas e sua tramitação na terceira seção; o momento pós-constituinte e o legado da reforma na quarta seção; e comentários conclusivos na quinta seção.

\section{A CONSTITUIÇÃO DE 1988 E A CONSTRUÇÃO DA HIPÓTESE}

Parece já bem documentada a importância decisiva da Constituição de 1988 na criação e expansão de políticas sociais no Brasil. Além do restabelecimento do Estado democrático de direito, a emergência de novos direitos sociais e a estruturação de um novo arcabouço para a proteção social têm ali sua origem (Draibe, 2002; Kerstenetzky, 2012).

Kerstenetzky (2012) destaca a mudança qualitativa promovida pela carta constitucional, que, como horizonte normativo, aproximou o Estado do bem-estar social brasileiro ao regime social-democrata europeu e à universalização das políticas sociais. A respeito dos direitos sociais, capítulo inexistente na Constituição de 1967, lê-se no Artigo 6o da Carta de 1988: "São direitos sociais a educação, a saúde, o trabalho, o lazer, a segurança, a previdência social, a proteção à maternidade e à infância, a assistência aos desamparados, na forma desta Constituição". Ampliação significativa de direitos trabalhistas é destacada por Draibe (2002) e Fagnani (1997), como a redução da jornada de trabalho, o aumento do período de licença-maternidade, a introdução de pagamento adicional para férias e a extensão da proibição do trabalho infantil.

Tão fundamental parece ser o marco, que a significativa redução da desigualdade de renda observada durante a primeira década do século XXI pode ser associada a ele (Kerstenetzky, 2017). Segundo estimativa recente, o salário mínimo piso dos benefícios sociais a partir de 1988, e, portanto, base para transferências previdenciárias e benefícios assistenciais, como o Benefício da Prestação Continuada (BPC) - teria sido o principal responsável pela queda do coeficiente de Gini entre 1995, quando tem início a política de valorização do mínimo, e 2014 (cf. Brito, Foguel \& Kerstenetzky, 2017) ${ }^{1}$. Contudo, ao que parece, a redução da desigualdade poderia ter sido ainda mais intensa - e possivelmente mais duradoura caso fossem efetivadas determinações constitucionais referentes à expansão dos serviços públicos sociais, de educação e saúde, universais e de qualidade. E ainda

\footnotetext{
${ }^{1}$ Nesse período, o coeficiente de Gini declinou de 0,61 para 0,52 (Brito, Foguel \& Kerstenetzky, 2017). Novos trabalhos que utilizam, além de pesquisas domiciliares, dados de declarações tributárias, retratando com maior precisão as rendas detidas pelo percentil superior, constatam que a desigualdade permaneceu estável. Mesmo esses estudos, contudo, admitem significativa queda da desigualdade dos rendimentos do trabalho no período (Medeiros \& Souza, 2016; Medeiros, Souza \& Castro, 2015A; 2015B, Morgan, 2017).
} 
mais profunda, caso a tributação progressiva figurasse com proeminência como forma de financiamento do gasto público - das políticas sociais, em particular.

Em que pese a não universalização efetiva dos serviços públicos sociais, o gasto público social, como percentual do PIB, dobrou nos vinte anos seguintes à Constituição, principalmente devido à crescente participação da previdência e da assistência social (Castro \& Afonso, 2009; Guerreiro, 2010). A carga tributária bruta seguiu a tendência, passando de $23 \%$, em 1988 , para cerca de $32 \%$ do PIB, em 2016 (CETAD, 2017; Orair et al., 2013). Ainda que boa parte tenha sido absorvida por uma dívida bruta crescente, recursos adicionais relativos e absolutos se voltaram para o financiamento dos novos gastos.

A elevação da carga tributária observada nas últimas décadas, no entanto, não foi acompanhada pela progressividade da arrecadação. Pelo contrário, a partir de 1988, a elevação dos recursos tem se valido de um sistema tributário cujo ônus recai desproporcionalmente sobre os mais pobres. Teria a própria Constituição, como sugerido em Kerstenetzky (2017), estabelecido limites para a expansão das oportunidades sociais efetivas que ela previra por via da interdição à progressividade? O paradoxo é assim descrito:

A Constituição não propugnou a tributação progressiva como esteio dos gastos, o que se revelaria essencial para a efetivação dos direitos nominalmente estendidos a todos os brasileiros [...]. Isso porque para sustentar o viés progressivo do gasto social seria necessário financiá-lo com impostos não regressivos, impostos cujo fato gerador fosse não o consumo, mas a renda e a riqueza, pois de outra forma onerariam justamente os indivíduos e famílias potenciais beneficiários do esforço redistributivo. Ademais, a necessidade de recursos adicionais para os serviços sociais públicos se impunha, para que fossem universais e de fato contemplassem integração social e não os conhecidos dualismos (Kerstenetzky, 2017, p.12).

De fato, apesar de articular no artigo 145 o importante princípio da capacidade contributiva - "sempre que possível os impostos terão caráter pessoal e serão graduados segundo a capacidade econômica do contribuinte" -, o "subprincípio" da progressividade não estava explícito na Constituição de 1988, sendo a única exceção o Imposto de Renda (Art. 153, $\mathbb{S} 2^{\circ}$, inc. I) (cf. Lukic, 2017)². Mesmo assim, a efetiva progressividade fica a depender de seu grau, que será matéria infraconstitucional: o número de faixas e as alíquotas incidentes (Idem).

O paradoxo abre questões. Como poderia o texto constitucional praticamente ignorar a exigência de progressividade? Alternativamente, teriam sido submetidas à Assembleia Constituinte propostas para promover equidade tributária? Em caso

\footnotetext{
${ }^{2}$ Lukic (2017) afirma ser o ITR outra exceção. Contudo, ao examinarmos a forma da CF 1988 não pudemos confirmar essa informação.
} 
positivo, o que se passou com elas, como tramitaram? Como conectar os desdobramentos posteriores, que intensificaram a injustiça fiscal no país, com esse processo?

Como já mencionado, identificamos uma proposta estruturada de reforma tributária incluindo questões de justiça fiscal, avançada por comissão instituída para assessorar tecnicamente os trabalhos do grupo constituinte encarregado do capítulo sobre tributação. Nas próximas seções, analisamos a proposta e seu encaminhamento e, posteriormente, seus desdobramentos pós-ANC, em termos da trajetória que é então inaugurada para o trato da questão tributária no país. Esse episódio se revela central para abrigar o paradoxo sob a forma hipotetizada - gasto social sim, desde que tributação progressiva não -, a "hipótese política".

Admitidamente, há outras formas possíveis de conciliação do paradoxo "gasto sim, progressividade não", menos indiciantes da "Constituição Cidadã". Além da referida mudança de convenção fiscal no mundo (Gobetti \& OraiR, 2016), "hipótese exógena", a noção de que uma oportunidade foi perdida por um lapso ou erro de avaliação, "hipótese do lapso", ou ainda a sugestão de consequência não pretendida (regressividade) de outras mudanças perseguidas (por exemplo, a descentralização dos tributos), "hipótese da inocência".

A hipótese do lapso, contudo, não parece particularmente convincente, uma vez que o tema foi tratado em profundidade e se a orientação progressiva não foi adotada, o motivo não terá sido sua ausência do debate constituinte. Quanto à hipótese exógena, dado que a questão da progressividade foi seriamente considerada, é notável que entre os argumentos contrários não tenha figurado com centralidade o da mudança de convenção tributária no mundo pós-anos $1980^{3}$. Finalmente, quanto à hipótese da inocência, aparentemente mais convincente, é possível, entretanto, afirmar, com base na documentação referida neste trabalho, que mesmo que não exatamente deliberados, os desdobramentos regressivos da reforma tributária eram previsíveis - o que parece dificultar o abandono da "hipótese política", a do acordo tácito. No mínimo, se considerou aceitável trocar uma coisa pela outra, isto é, a progressividade pela descentralização, como discutiremos mais adiante na próxima seção. Outro elemento em favor da hipótese política foram argumentos apelando para a generalidade da Constituição, a qual não deveria especificar abrangência de impostos e alíquotas - inconsistentes, como argumentaremos a seguir. A hipótese de acordo tácito, embora não diretamente verificável dada a dificuldade de se recolher evidências desse tipo, não parece passível de descarte.

\footnotetext{
${ }^{3}$ Segundo a qual a política redistributiva deveria ser exercida via gasto e não tributação, que distorceria incentivos econômicos. $\mathrm{Na}$ verdade, tendências internacionais foram mobilizadas pelos dois lados do debate, o pró-progressividade e o seu antípoda. A hipótese "exógena” poderia ser entendida de modo complementar à hipótese política que sustentamos na medida em que se acredite que a formação dessa convenção tributária internacional a partir da década de 1980 seja proveniente de interesses domésticos nacionais. Alguns dos pesquisadores que defendiam maior progressividade no sistema tributário brasileiro durante o processo da Constituinte parecem ter posteriormente aderido a essa convenção, privilegiando a redução da desigualdade por meio do gasto, em detrimento da tributação. Agradecemos a um parecerista anônimo por destacar essa perspectiva.
} 


\section{AS PROPOSTAS DA CRETAD À CONSTITUINTE}

Os últimos anos da década de 1980 testemunharam importantes mudanças políticas e econômicas. O país assistiu ao crepúsculo do regime militar com esperanças de que a redemocratização promovesse diminuição da inflação e redistribuição de renda (Castro, 2005), entre outras mudanças. Especificamente no que concerne à justiça tributária, a expectativa de redirecionamento era considerável, uma vez que a reforma de 1966 e a Carta de 1967 haviam eliminado o princípio da capacidade contributiva, presente na Constituição de 1946. É nesse contexto que, junto a alterações nas ordens social, política e econômica, foram apresentadas propostas para a reforma do sistema tributário à Assembleia Constituinte.

No âmbito da Constituinte, entre as diversas correntes que advogavam mudanças no sistema tributário, duas se destacaram durante os debates da comissão temática, a Comissão do Sistema Tributário, Orçamento e Finanças ${ }^{4}$ (Comissão de Tributação, doravante). A primeira, endossada pela Comissão Afonso Arinos instituída pelo presidente José Sarney, sugeria que pequenos ajustes seriam suficientes para corrigir os rumos do sistema, apenas eliminando distorções introduzidas após a reforma tributária de 1966. Para esse grupo, “a estrutura tributária legada pelos governos militares ao país constituiria uma preciosa herança que não poderia ser desprezada" (Oliveira, 1987, p.116; Dornelles, 2008). A segunda corrente propunha uma profunda transformação que tornasse o sistema tributário mais moderno, eliminando distorções agravadas por casuísmos do período autoritário, recuperasse a capacidade de gasto do Estado comprometida nos anos de recessão, e priorizasse os princípios da equidade e do federalismo (OLIVEIRA, 1987; Rezende et al., 1987).

Essa segunda corrente era portadora das proposições da Comissão da Reforma Tributária e Descentralização Administrativo-Financeira (CRETAD), instituída entre 1985 e 1987 pela Secretaria de Planejamento (SEPLAN) com o objetivo de realizar estudos sobre o sistema tributário nacional e assessorar a Comissão de Tributação na elaboração de propostas à Constituição (Fagnani, 1987; Oliveira, 1987; Rezende \& Afonso, 1987; Rezende et al., 1987) ${ }^{5}$.

Além de incluir entre seus objetivos a promoção de descentralização, capacidade fiscal, modernização, garantias contra o arbítrio do Estado e a atribuição de

\footnotetext{
${ }^{4}$ Os trabalhos da Assembleia Constituinte foram organizados a partir de oito comissões temáticas e uma Comissão de Sistematização. O debate que nos concerne envolvia a Comissão do Sistema Tributário, Orçamento e Finanças, composta pelas subcomissões de Tributos, Participação e Distribuição das Receitas; de Orçamento e Fiscalização Financeira; e do Sistema Financeiro (Lima et al., 2013).

${ }^{5}$ As propostas da CRETAD foram reunidas nos documentos "Estudos para a Reforma Tributária", organizados pelo Instituto de Pesquisa Econômica Aplicada (IPEA). Também ficaram conhecidas como "propostas do IPEA" ou "Projeto IPEA". Os estudos foram divididos em cinco tomos. O primeiro apresenta as propostas (Rezende et al., 1987), e os demais as aprofundam em seguimentos: tributação de renda e patrimônio (Giffoni \& Villela, 1987); tributação de mercadorias e serviços (Varsano, 1987); contribuições sociais (Rezende \& Azeredo, 1987); e federalismo fiscal (Afonso \& Lobo, 1987).
} 
maior controle ao poder legislativo, a proposta de reforma tributária da CRETAD abrigava um conjunto significativo de iniciativas visando ao aumento da progressividade do sistema. $\mathrm{Na}$ verdade, seus dois eixos básicos eram a promoção de equidade fiscal e autonomia federativa. A avaliação geral era de que o sistema que então vigorava, fruto de reformas realizadas durante a década de 1960, desconsiderava questões relacionadas "à distribuição equitativa do ônus tributário entre os membros da sociedade e à distribuição das competências e dos recursos entre esferas da federação" (Oliveira, 1987, p.116). O modelo anterior teria sido concebido com o objetivo de "estimular o crescimento acelerado a todo custo e manter sob a tutela do Estado autoritário as esferas subnacionais" (Oliveira, 1987, p.116; Rezende et al., 1987).

As propostas orientadas para a equidade partiam do reconhecimento de que as novas atribuições constitucionais exigiriam um novo padrão de gasto público e de que a estrutura da carga fiscal era marcada por acentuada regressividade. A CRETAD constatou que "o peso dos tributos no orçamento doméstico declina[va] de forma acentuada à medida que aumenta[va] o nível de rendimentos" (Rezende et al., 1987, p.2). O diagnóstico de regressividade, semelhante ao que se faz atualmente (Gobetti \& Orair, 2016; PinHEIRO et al., 2017), sinalizava a forte participação dos impostos indiretos e a desigualdade de tratamento que opunha uma rigorosa tributação sobre os rendimentos do trabalho a "brechas no tratamento fiscal dos rendimentos e ganhos de capital, que atenuam a progressividade do imposto de renda" (Rezende et al., 1987, p.2).

A partir dessas constatações, o conjunto de propostas motivadas por maior justiça fiscal indicava a necessidade de "uma ampla revisão das bases de incidência dos tributos diretos e indiretos, de modo a torná-las mais abrangentes, mais eficientes e menos fragmentadas" (Rezende et al., 1987, p.5). Mais especificamente, propunha-se a adoção entre outras das seguintes medidas: a) tornar o imposto de renda abrangente, conferindo tratamento idêntico para rendimentos do trabalho e do capital, passando estes últimos a integrar sua tabela progressiva; b) criar um imposto sobre patrimônio líquido para pessoas físicas; e c) criar um imposto sobre heranças e doações (Oliveira, 1987; Rezende et al., 1987).

Cabem alguns esclarecimentos sobre cada uma das propostas. A incorporação integral dos ganhos e rendimentos de capital ao imposto de renda, tornando-o o mais abrangente possível, tinha como motivação a constatação de que os rendimentos do trabalho assalariado estavam amplamente sobrerrepresentados na renda sujeita à tributação progressiva, em virtude de tratamento privilegiado ao capital ${ }^{6}$. Nesse sentido, propôs-se: “Toda a renda anual auferida deverá compor a base de cálculo, qualquer que seja sua origem - rendimentos de trabalho, rendimentos

\footnotetext{
${ }^{6}$ No período, grande parte dos rendimentos de capital sujeitos ao IR era tributada exclusivamente na fonte, no lugar da tributação progressiva da declaração. Além disso, uma parcela significativa desses rendimentos estava isenta de tributação (Rezende et al., 1987).
} 
e ganhos de capital - tributados progressivamente na declaração anual do contribuinte pessoa física" (Rezende et al., 1987, p.9).

Com relação às propostas que incidiam sobre a riqueza e sua transmissão - o imposto geral sobre patrimônio líquido para pessoas físicas (IPL) e o imposto sobre sucessões (heranças) e doações (ISD) -, ao justificá-las, os autores inicialmente esclarecem a diferença entre renda e patrimônio e a diferença entre suas distribuições, sendo a concentração do segundo sempre bastante superior à da primeira. Assim sendo, argumentam, esses impostos teriam efetiva capacidade de conferir maior progressividade ao sistema - e, uma vez criados, contribuiriam para reduzir a discrepância do Brasil em relação a um conjunto significativo de países, onde a incidência tributária sobre o patrimônio era não desprezível ${ }^{7}$.

Especificamente com relação ao imposto geral sobre o patrimônio, as propostas insistem na necessária atenção ao estoque de riqueza, em acréscimo aos fluxos de renda:

Resta por tributar o estoque patrimonial possuído e desfrutado, mas não realizado, inalcançável pela tributação que incide apenas sobre os fluxos de renda ou sobre a propriedade imobiliária. Impressiona constatar vastos segmentos da riqueza nacional que permanecerão à margem da responsabilidade fiscal enquanto não se fizer uso de técnicas apropriadas à ampla taxação de estoques (Rezende et al., 1987, p.13).

A proposta do IPL é bastante detalhada: o imposto incidiria sobre o patrimônio líquido de dívidas, com exonerações para o pequeno patrimônio (a pequena poupança, o pequeno capital produtivo, a residência habitada pelo proprietário, etc.), teto de contribuição e provisões para evitar bitributação, como mecanismos de compensação e interdedutibilidade de impostos; há referência a alíquotas progressivas e preocupação explícita de relacionar a proposta com o já experimentado em outras partes do mundo (Giffoni \& Villela, 1987; Rezende et al., 1987).

Ademais, a tributação sobre patrimônio deveria ser complementada pelo imposto sobre heranças e doações, extinto na reforma tributária de 1966. A expectativa era a de que esse imposto, com alíquotas progressivas, contribuiria para a desconcentração da riqueza - de novo, como indicavam vários casos internacionais. "Enquanto o IPL será um tributo sobre a fruição do estoque patrimonial, este imposto gravará a acessão gratuita àquele estoque" (Rezende Et Al., 1987, P.14; Giffoni \& Villela, 1987).

Com a criação desses dois tributos, a reforma da CRETAD visava a formar um "conjunto orgânico de impostos integrados pelo IR de base abrangente, o IPL e o ISD, todos de competência exclusiva da União, que [...] poderá melhorar a progressividade da tributação direta" (Rezende et al., 1987, p.14).

\footnotetext{
${ }^{7} \mathrm{Em}$ 1984, os impostos sobre a propriedade representavam 0,4\% do PIB no Brasil, mas 3\% nos EUA, 4,7\% no Reino Unido, 2,6\% no Japão, 2\% na França, e 1,8\% na OCDE (Giffoni \& Villela, 1987).
} 
Com relação aos tributos indiretos, ainda que tivessem sido reconhecidas suas implicações regressivas, as mudanças propostas seriam quase inócuas em termos de progressividade. A principal medida era a extinção do imposto sobre produtos industrializados (IPI) e a substituição do imposto sobre circulação de mercadorias (ICM), do imposto sobre serviços (ISS) e de outros impostos indiretos por um novo "imposto sobre o valor agregado" (IVA), a encargo dos estados, que incidiria sobre todas as mercadorias e serviços. O IVA também substituiria algumas contribuições sociais, como o FINSOCIAL e o salário-educação. O propósito era aumentar a autonomia fiscal de estados e municípios, promovendo descentralização administrativo-financeira. Havia a vaga esperança de que o IVA fosse "mais aderente aos princípios de eficiência e equidade" (Rezende et al., 1987, p.5). O possível efeito progressivo desse imposto seria proveniente da equiparação da tributação de serviços e mercadorias, uma vez que os serviços, então subtributados, são mais consumidos pelas classes de renda mais altas (Rezende et al., 1987). Contudo, a ausência de ousadia na busca de equidade na tributação indireta foi justificada por uma descrença dos técnicos da CRETAD quanto à sua efetividade. Mais ainda, havia a expectativa de que a ampliação dos impostos diretos progressivos, se tal houvesse, e sua partilha com os estados permitiriam menores alíquotas e menor participação do IVA na receita tributária, atenuando os efeitos regressivos deste imposto e restaurando a progressividade da carga tributária como um todo (Varsano, 1987).

Mesmo com a ressalva acerca da tributação indireta, parece lícito concluir que as propostas da CRETAD, se incorporadas ao projeto de reforma tributária, concorreriam para promoção de maior justiça fiscal, em virtude da maior abrangência conferida ao IR e da tributação efetiva e progressiva do patrimônio e dos rendimentos do capital. Essa, por exemplo, é a avaliação independente de Oliveira (1987), à época:

As propostas da CRETAD resgatariam princípios fundamentais das finanças públicas de uma sociedade que se pretende justa e democrática. As propostas de ampliação da base de tributação do imposto de renda e de extinção dos privilégios de que desfrutam determinados segmentos da sociedade - agricultura, mercado de capitais, investidores do mercado financeiro, etc. - em relação à sua incidência transformam-no, concretamente - ou pelo menos criam as condições para tanto -, em um imposto abrangente, que tem o mérito de não discriminar a origem do rendimento para sua imposição. Por outro lado, a sugestão para a instituição de impostos sobre o patrimônio tem a pretensão de gravar a riqueza acumulada que não é alcançada, em parte porque não se realiza, por outras formas de tributação direta, desempenhando, assim, o papel de instrumento de justiça fiscal, ao mesmo tempo que, secundariamente, constitui uma fonte de receita adicional para os cofres públicos (Oliveira, 1987, p.120). 


\section{O silencioso desmoronamento}

Como vimos, as propostas para reforma do sistema tributário concebidas pela CRETAD respondiam a necessidades previamente identificadas de alterações na abrangência e progressividade da tributação. Menciona-se reiteradamente que elas implicariam caso implementadas em aumento significativo da arrecadação e da equidade do sistema tributário. Em outras palavras: as lacunas a que viriam preencher, bem como os prejuízos que a desconsideração de seus cuidados acarretaria, eram de conhecimento geral na esfera deliberativa relevante. Em princípio, pois, o processo constituinte não parece ter ignorado as exigências fiscais das novas atribuições do Estado social. Contudo, uma a uma, estas propostas foram desconstruídas, e é à descrição desses percursos que nos voltaremos agora.

Ainda na Comissão de Tributação, descartou-se a proposta de arrecadação progressiva dos rendimentos do capital, com o argumento de que a inclusão explícita de bases mais abrangentes para a tributação da renda não deveria ser matéria constitucional. A propósito, havia intenso debate, entre os constituintes, a respeito do que deveria ou não estar presente no texto constitucional (Souza, 2001). Sobre o tópico em questão, ainda que não tanto sobre outros ${ }^{8}$, acabou prevalecendo a recomendação do presidente da Comissão, Francisco Dornelles, finalmente acatada também pelo relator José Serra, de que a carta fosse "a mais sucinta possível" 9 Mais tarde, justificando essa posição, Dornelles declararia: "[u]ma Constituição destinada a reger a vida de um povo, de forma durável e estável, há de conter apenas os princípios fundamentais" (Dornelles, 2008, p.3).

A descrição de técnicos da CRETAD sobre esse momento do processo constituinte revelaria que "o debate sobre mudanças no imposto de renda foi adiado para uma segunda etapa do processo de reforma tributária", passando a depender - abrangência, alíquotas e isenções - de legislação complementar e ordinária (Rezende \& Afonso, 1987, p.18). É preciso, contudo, destacar a aprovação já no âmbito da Comissão de Tributação do importante inciso segundo o qual o IR seria "informado pelos critérios da generalidade, da universalidade e da progressividade" 10. A universalidade equivale a considerar "todas as rendas e proventos das pessoas"; a generalidade, "todas as pessoas", sem discriminações ou privilégios; e a progressividade, o "corolário e modo de realização dos princípios da capacidade contributiva e da igualdade", como o princípio de que "os que tenham mais, os que podem arcar com um maior ônus na distribuição da carga tributária, paguem mais

\footnotetext{
${ }^{8}$ A Constituição previa percentuais exatos do IR e do IPI que deveriam ser transferidos da União para estados e municípios, por exemplo. Também há percentuais específicos para a descentralização da receita de alguns impostos, como o ITR e o IPVA.

${ }^{9}$ Justificando-se, Serra declarou na ocasião o seguinte: "Os tributaristas que nos assessoraram são testemunhas do nosso empenho em procurar a saída pelo lado constitucional, mas viraríamos objeto de curiosidade mundial se fixássemos na Constituição alíquotas de impostos muito detalhadas, sistemáticas de cobrança, de abrangência etc.” (Finanças, 1988, p.137).
}

${ }^{10}$ Art. 153, \$ 2, inc. I (Brasil, 2016). 
imposto" (Queiroz, 2004, p.36-38). Não obstante, como veremos, esses “princípios fundamentais" não foram seguidos ou o foram de modo incipiente.

O imposto sobre heranças e doações, presente na CF 1946, suprimido pela reforma tributária de 1965-1966 e ausente da CF 1967, logrou ser reintroduzido. Em contraste com o proposto pela CRETAD, a Comissão de Tributação atribuiu esse encargo aos estados, não à União, por meio da cobrança de "impostos sobre 'causa mortis' e doação, de quaisquer bens ou direitos, cujas alíquotas serão progressivas" ${ }^{11}$. Ao longo dos trabalhos da Comissão de Sistematização, no entanto, ainda antes do encaminhamento ao plenário, a última parte da sentença - "cujas alíquotas serão progressivas" - foi suprimida (Lima et al., 2013). Em votação específica sobre esse trecho, acabou prevalecendo o curioso argumento de que seria ocioso engessar esse imposto com alíquotas progressivas, posto que já havia a recomendação de que impostos seriam progressivos sempre que possível.

Tampouco foram integralmente acatadas as modificações sugeridas na tributação de mercadorias e serviços - das quais, de todo modo, se esperava impacto diminuto sobre a progressividade. O IVA, um imposto cobrado sobre o consumo, foi descartado por representantes de todas as regiões com o argumento de maior dificuldade de fiscalização e potencial perda de arrecadação, apesar de claramente favorecer, por meio da incidência pelo princípio do destino, os estados menos desenvolvidos em detrimento dos estados do Sul e do Sudeste (Oliveira, 1992). Com a rejeição da proposta do IVA, naufragou a sugestão de corrigir a subtributação dos serviços. Embora o ICM, transformado no imposto sobre circulação de mercadorias e serviços (ICMS), tenha tido sua base de incidência ampliada, era todavia mais estreita do que a embutida no IVA ${ }^{12}$. Além disso, os estados ganharam autonomia para fixar suas alíquotas (Rezende, 2009).

Finalmente, o imposto geral sobre patrimônio líquido foi descartado, pela diferença de apenas um voto, ainda na Comissão de Tributação. O presidente da Comissão, Francisco Dornelles, havia declarado em artigo publicado na Folha de S.Paulo em meio ao processo constituinte algumas das muitas razões invocadas:

[...] o aumento da propensão ao consumo, entesouramento, fuga de capitais de setores produtivos, fugas de capitais para o exterior e aumento de aplicações em papéis ao portador, em ouro, em dólar e em outros ativos mais facilmente sonegáveis, em detrimento de aplicações em setores produtivos. Acresce a essas consequências perversas e indesejadas o fato indiscutível de que as dificuldades de arrecadação e de fiscalização tornam o imposto injusto, porque a eles somente se sujeitarão os contribuintes honestos e os que não se utilizarem das fáceis técnicas de evasão que esse tipo de tributação enseja (Dornelles, 1987, p.3).

\footnotetext{
${ }^{11}$ Art. 155, inc. I (Brasil, 2016).

12 Ao ICMS foi incorporada a produção de energia elétrica e de petróleo e derivados, além dos serviços de comunicação e de transporte entre estados e municípios (Rezende, 2009).
} 
Como espécie de compensação, já na Comissão de Sistematização, e à última hora, foi inserida a tributação de grandes fortunas. Ainda que previsto na Constituição, o imposto sobre grandes fortunas nunca foi regulamentado. Integrantes da CRETAD já previam esse desfecho frustrante, apontando desde então "a duvidosa eficácia de imposto sobre grandes fortunas, ao invés de patrimônio líquido" (Rezende \& AFONSO, 1987, p.33). Os autores parecem se referir à imprecisão do termo "grandes fortunas", em contraste com o apuro técnico com que a CRETAD concebeu o imposto sobre o patrimônio líquido.

Entre as supressões, essa última parece ter sido, ao menos inicialmente, a mais sentida. Havia grande expectativa quanto a mudanças na incipiente tributação da riqueza no país. "A reformulação dos tributos incidentes sobre patrimônio é prioritária na perseguição de maior justiça fiscal”, afirmava o relatório da CRETAD (Rezende et al., 1987, p.5). Do mesmo modo, Rezende e Afonso (1987) observavam que "um dos avanços mais esperados na discriminação das competências tributárias na nova Constituição dizia respeito à definição de imposto sobre patrimônio líquido" (Rezende \& Afonso, 1987, p.33).

Em análise crítica das propostas da CRETAD, realizada antes das modificações introduzidas na Comissão de Tributação, Oliveira (1987) antevia os obstáculos e seus prováveis desdobramentos.

Sem entrar na discussão da dimensão que pode assumir a polêmica em torno da sugestão para a criação de impostos sobre o patrimônio, dadas as resistências seculares que existem por parte das classes dominantes em relação à medida - ainda que eles já existam na maioria dos países desenvolvidos e até mesmo em alguns países do Terceiro Mundo - é indiscutível que sua rejeição poderá comprometer o objetivo de imprimir um perfil progressivo à estrutura tributária e de criar fontes adicionais de recursos para os cofres públicos. Se isso ocorrer - o que é possível - um de seus objetivos se esfuma, a menos que o IR aprovado em sua totalidade seja capaz de imprimir os contornos desejados ao sistema (Oliveira, 1987, p.122).

Vimos, contudo, que a aposta no IR tinha sido severamente afetada com a exclusão de explícita progressividade sobre os rendimentos do capital, sob o argumento da generalidade da Constituição. Contudo, o golpe sobre a progressividade seria ainda mais profundo, com o bloqueio da possibilidade de que a tributação direta protagonizasse a carga tributária. Como veremos, a própria Constituição criou mecanismos que, além de desencorajar esse caminho, acabaram por contribuir para tornar o sistema ainda mais regressivo.

\section{A interdição constitucional da tributação direta}

Seguiremos a avaliação de Rezende e Afonso (1987) sobre as modificações sofridas pelas propostas da CRETAD na Comissão de Sistematização, pouco antes 
do texto ser encaminhado ao plenário, onde foram realizadas, sobretudo, mudanças formais (Lima, 2013). A principal característica da reforma até aquele momento seria o "grande avanço na direção de uma significativa descentralização da receita tributária, mediante redivisão de competências e ampliação das transferências federais para estados e municípios" (Rezende \& Afonso, 1987, p.6). Após as modificações, ainda que tenha havido certa redistribuição de competências, o impacto mais significativo foi o "violento acréscimo" do percentual da receita de impostos federais que passariam a ser transferidos, da União, para os demais níveis de governo (Rezende \& Afonso, 1987).

De modo geral, a despeito de recuos cruciais em relação à equidade do sistema, a reforma tributária obteve soluções relativamente consensuais, tornando-se um dos tópicos menos alterados durante o processo constituinte (Dornelles, 2008; Rezende \& Afonso, 1987). O acordo só teria sido possível, contudo, graças à imposição de grandes perdas à União. Mais de $80 \%$ dessas perdas seriam decorrentes do aumento da repartição do IR e do IPI para estados e municípios. Ainda que as propostas da CRETAD também almejassem descentralização, a repartição sugerida era notavelmente menor que aquela aprovada pela Constituinte (Rezende \& Afonso, 1987$)^{13}$.

Como as perdas da União seriam acompanhadas de novas atribuições constitucionais, eram urgentes medidas para ampliar a arrecadação dos tributos que permaneceriam sob competência federal. Com isso em mente, Rezende e Afonso (1987) temiam desdobramentos regressivos, notando a montagem de uma provável "armadilha": o aumento da porcentagem do IR e do IPI destinada aos fundos de participação de estados e municípios faria com que "o acréscimo nesses tributos [tivesse] que ser bastante significativo para que a receita da União se recuperasse", já que boa parte do valor aumentado teria de ser transferido (Rezende \& Afonso, 1987, p.18). O que eles anteviam, em outras palavras, era que com o substancial repasse do IR e do IPI a estados e municípios acordados na Constituição, esta teria reduzido drasticamente incentivos para aumentos progressivos da arrecadação. Não compensaria o esforço de "duras batalhas políticas" para a aprovação de "mudanças que afetam interesses poderosamente estabelecidos, se os ganhos financeiros a serem obtidos diluem-se em frações pouco expressivas do ponto de vista de cada uma das partes interessadas" (Rezende \& Afonso, 1987, p.20). O objetivo de reduzir a regressividade do sistema tributário estaria diretamente ameaçado pelo modelo de descentralização acolhido.

Os autores chegaram a crer em desfecho positivo: as perdas da arrecadação da União poderiam estimular, posteriormente, "profundas reformulações" na legis-

\footnotetext{
${ }^{13}$ Rezende e Afonso (1987) estimaram a queda da participação da arrecadação do governo federal para $36 \%$ (contra $45 \%$ na Constituição anterior), enquanto as participações de estados e municípios passariam de $37 \%$ e $18 \%$ para $41 \%$ e $23 \%$, respectivamente. Se atendidas as propostas da CRETAD, a participação da União teria passado de $45 \%$ para $41 \%$. Antes da Constituição de 1988 , eram transferidos cerca de $30 \%$ do IR e do IPI para estados e municípios (Rezende \& Afonso, 1987). A Constituição determinou que a transferência passasse a ser de $47 \%$ desses impostos.
} 
lação do imposto de renda. Esse aumento forçado na carga tributária seria alcançado por meio da "eliminação dos privilégios existentes e a reformulação do caótico e injusto sistema de incentivos e de outros benefícios fiscais", que por sua vez levaria à "melhoria significativa da progressividade do sistema tributário", gerando acréscimos importantes à receita federal (Rezende \& Afonso, 1987, p.18). Estas mudanças estruturais no imposto de renda seriam, então, a principal alternativa para que a carga tributária pudesse ser elevada sem agravar a regressividade do sistema (Rezende \& Afonso, 1987).

Mas, Rezende e Afonso alertavam que, caso suas esperanças não se concretizassem, e não fosse possível romper com a resistência a mudanças no IR, o "caminho alternativo" para compensar as perdas de arrecadação da União seria a ampliação das bases de incidência das contribuições sociais, prevista na nova Constituição. Esse caminho apresentava de imediato dois problemas: além das restrições ao uso das contribuições sociais, em tese vinculadas ao sistema de seguridade social, elas possuiriam caráter regressivo (Rezende \& Afonso, 1987).

Em síntese, o acordo em torno à tributação desencorajou a busca por ampliação do IR - um imposto progressivo -, ao mesmo tempo em que estimulou a emergência de alternativas regressivas de arrecadação, como as contribuições sociais (Rezende \& Afonso, 1987). Assim, a descentralização tributária acabou por contribuir para inibir a equidade fiscal.

Muito embora Rezende e Afonso (1987) tenham julgado "bastante satisfatórios” os resultados das transformações sofridas pelas propostas da CRETAD na Constituinte, não se furtaram a reconhecer graves consequências para a justiça fiscal:

Em resumo, [...] não há garantias, por enquanto, de que o projeto de reforma tributária traga maiores avanços no que diz respeito à redução das notórias injustiças na repartição do ônus tributário. A mobilização dos interesses regionais e corporativos jogou para segundo plano as questões mais importantes para o aperfeiçoamento do sistema, no tocante a princípios de equidade e justiça (Rezende \& Afonso, 1987, p.20).

Em suma, a concepção tributária que acompanhou a emergência da nova Constituição foi perdendo, pouco a pouco, o viés progressivo. As propostas da CRETAD nessa direção foram sucessivamente desvirtuadas ou rejeitadas, ao mesmo tempo em que prevalecia a causa de maior autonomia a estados e municípios - a qual, na avaliação de especialistas como Oliveira (1987), estava neutralizada no passado recente por um Estado centralizador e autoritário. A ausência de medidas pró-progressividade, junto com o novo caminho que se abria para o financiamento do Estado, não apenas impediu a ascensão de um Estado fiscal mais redistributivo, como abriu caminho para as feições cada vez mais regressivas assumidas pelo sistema tributário. Na próxima seção, acompanharemos momentos decisivos na reconfiguração regressiva desse sistema, que não se podem desvincular de mecanismos criados pela carta constitucional. 


\section{PÓS-CONSTITUINTE: O PROCESSO DE REGULAMENTAÇÃO INFRACONSTITUCIONAL OU O LEGADO DA REFORMA}

A regulamentação seguinte à promulgação da Constituição esteve associada a duas importantes conjunturas: a grave crise fiscal e a transição democrática ainda em curso. Sob a influência crescente dos preceitos neoliberais para a América Latina, o país assistiu a um conjunto de esforços no sentido da gradual diminuição da participação do Estado na economia (Castro, 2005). A transição democrática, por seu turno, foi marcada pelo jogo entre forças "progressistas" e "conservadoras", ainda no momento constituinte (Pilatti, 2008), ou "reformistas" e "contrarreformistas" no momento pós-Constituição, comprometidas, respectivamente, com o avanço e o bloqueio da agenda de direitos sociais (Fagnani, 1997). No que respeita à questão tributária, é possível afirmar que enquanto o movimento conservador se empenhou em reduzir ao mínimo as instruções constitucionais quanto à progressividade, o movimento de contrarreforma, que prevaleceu nos primeiros anos pós-Constituição (Draibe, 2002; Fagnani, 1997), cuidou para explorar ao máximo brechas e lacunas via regulamentação redutora de progressividade, como veremos.

Pesquisadores da CRETAD já alertavam em 1987 para a importância crucial do processo de regulamentação, novo campo de disputa onde forças antagônicas se confrontariam. Conforme admitido por Rezende e Afonso,

O Projeto de Constituição define apenas a direção das reformas, mas não as consolida, como bem ilustra o caso tributário. A elaboração da legislação complementar e ordinária, bem como outras medidas a serem adotadas pelas autoridades governamentais das mais distintas áreas, assume grande importância para conclusão do processo de reforma fiscal (Rezende \& Afonso, 1987, p.42).

A maior preocupação desses técnicos era com a regulamentação do imposto sobre a renda, sobretudo no que dizia respeito à "adoção do princípio de bases abrangentes e reformulação de incentivos e benefícios fiscais" (Rezende \& Afonso, 1987, p.42).

A sucessão de leis infraconstitucionais acabou por confirmar os temores desses especialistas. Inicialmente, acompanhando a diretriz constitucional de universalidade, em dezembro de 1988, dois meses após a promulgação da nova carta, o presidente José Sarney revogou "todos os dispositivos legais de isenção ou exclusão, da base de cálculo do imposto de renda das pessoas físicas, de rendimentos e proventos de qualquer natureza" ${ }^{14}$. No entanto, essa mesma lei instituiu duas medidas frontalmente redutoras do grau de progressividade do IR: ela diminuiu o número de alíquotas de dez para apenas duas e reduziu a alíquota máxima pela metade, de $50 \%$ para 25\% (Gobetti \& Orair, 2016; Queiroz, 2004) ${ }^{15}$.

\footnotetext{
${ }^{14}$ Lei 7.713 .

${ }^{15}$ Até então, havia dez alíquotas, entre 5\% e 50\%, oriundas do Decreto-lei n ${ }^{\circ} 2.356$, de 1987. Com as
} 
A expectativa de que rendimentos e ganhos de capital estivessem sujeitos à tabela progressiva teve vida curta. Em 1990, passou a valer alíquota fixa, de $25 \%$, para os ganhos de capital de pessoa física - posteriormente reduzida para $15 \%$, em janeiro de $1995^{16}$. Passava, portanto, a vigorar um sistema híbrido, contrário à recomendação de capacidade econômica do contribuinte, pelo qual parte da renda era tributada segundo a tabela progressiva, como os rendimentos do trabalho, enquanto outros rendimentos, como os ganhos de capital, eram tributados com alíquota fixa (Gutierrez, 2009).

Em dezembro de 1995, o imposto sobre a renda ganharia contornos ainda mais regressivos - e idiossincráticos. A tributação sobre o lucro das empresas - até então em $34 \%$, computados o IRPJ e a CSLL - passou a ser significativamente menor graças à dedução de uma despesa fictícia, a taxa de juros sobre o capital próprio (Gobetti \& Orair, 2016). Ademais, os dividendos transferidos aos acionistas (pessoas físicas), antes tributados a $15 \%$ como os demais ganhos de capital, passaram a estar isentos (Gobetti \& Orair, 2016; Queiroz, 2004) ${ }^{17}$.

Em suma, o anseio de que a regulamentação posterior à Constituição seguisse seus "princípios fundamentais" e conferisse maior equidade ao IR não se realizou. Ao contrário, as vagas diretrizes não se constituíram em barreira legal suficiente para impedir que a progressividade do imposto fosse significativamente comprometida pela legislação infraconstitucional, e viesse a se constituir em aspecto duradouro de nosso sistema tributário. De fato, chamou a atenção a celeridade com que apenas promulgada a Carta o imposto de renda fora brutalmente reduzido e sobejamente compensada a extensão da abrangência de sua incidência ao capital; poucos anos mais tarde, esta viria a ser, de fato, suprimida com novos tratamentos privilegiados e isenções.

A participação do IR na receita tributária acusa o golpe, encolhendo de 16,3\% para 14,2\% entre 1986 e 1991 (Rezende et al., 1987; SRF, 1997). Ademais, como documentado em alguns estudos, a estrutura do IR se torna pouco progressiva - já que ele é regressivo nas mais altas rendas, onde se concentram os rendimentos de capital que se beneficiam de isenções ou alíquotas fixas baixas (Gobetti, Orair, 2016 \& Pinheiro et al., 2017). A remanescente progressividade do imposto é explicada pelas alíquotas incidentes sobre os rendimentos do trabalho. Como consequência, observa-se seu diminuto efeito redistributivo: uma queda no índice de Gini de 2,8\% (Gobetti \& Orair 2016), redução bastante inferior à obtida, em média, pelos países da OCDE (6\%, conforme Jourmard et al., 2012), e mesmo por países vizinhos na

mudanças, as duas únicas alíquotas passaram a ser de $10 \%$ e 25\% (Queiroz, 2004). Para a discussão jurídica acerca da ideia de que a expressiva diminuição das alíquotas fere o princípio da progressividade, ver Queiroz (2004).

${ }^{16}$ Leis 8.134 e 8.981 , respectivamente.

${ }^{17}$ Lei 9.249. A isenção fiscal dos dividendos é procedimento inusitado no cenário internacional. Entre os 34 países da Organização para a Cooperação e Desenvolvimento Econômico (OCDE), a Estônia é o único a isentar os dividendos, como faz o Brasil. Como resultado, a parcela dos lucros arrecadada pelo Estado sob a forma de tributos é muito mais alta nos outros países, 43,1\% em média na OECD, do que no Brasil, 34\% (Gobetti \& Orair, 2016). 
região (2,9\% no Chile, 3,5\% na Argentina, 4\% no Uruguai e 4,7\% no México, conforme Hanni et al., 2015) ${ }^{18}$.

Quanto à regulamentação dos outros dispositivos constitucionais relacionados à equidade fiscal, cabem alguns comentários. Para o imposto sobre herança e doações, atribuído aos estados pela Constituição, o Senado instituiu, em 1992, a alíquota máxima de $8 \%$, deixando a critério dos estados a incidência ou não de alíquotas progressivas ${ }^{19}$. A maior parte dos estados possui alíquotas entre $2 \%$ e $4 \%$. Conforme já mencionado, a exigência de progressividade estava prevista, mas foi retirada nas últimas etapas da ANC; na prática, os estados utilizam apenas uma alíquota e raramente cobram a alíquota máxima permitida (Amapá, Bahia, Ceará e Santa Catarina eram as únicas exceções em 2015, segundo Rausch (2015)). O imposto sobre grandes fortunas, pequeno alento ante a derrota do imposto geral sobre o patrimônio líquido, jamais foi regulamentado, a despeito de variadas tentativas, a primeira delas ainda em 1989.

\section{O crescimento das contribuições sociais}

A regressividade do sistema tributário brasileiro, como já observado, é explicada não somente pela baixa progressividade do principal tributo progressivo, o IR, e pela diminuta tributação do patrimônio $(4,67 \%$ da receita tributária ou 1,51\% do PIB em 2016 (CETAD, 2017)), mas também pela participação desproporcional da tributação indireta.

Conforme previsto pelos autores que já em 1987 avaliavam os rumos das propostas da CRETAD, a Constituição abriu o caminho para que esta participação se tornasse ainda maior.

Desde 1988 vem se observando expressiva elevação da carga tributária bruta, que passou do patamar de 23\% para cerca de 32\% do PIB em 2016 (CETAD, 2017; Orair et al., 2013). Diversos estudos têm destacado o papel das onerações tributárias, sobretudo das contribuições sociais, nesse processo (Orair et al., 2013).

$\mathrm{O}$ crescimento das contribuições sociais tem dois momentos distintos. Segundo Orair et al. (2013), nos anos imediatamente seguintes à Constituição, visava a obter recursos para viabilizar a ampliação das obrigações do Estado, com a introdução da seguridade social (saúde, previdência e assistência social) e a instituição do salário mínimo como piso dos benefícios constitucionais ${ }^{20}$. A partir de 1999, contudo, após a adoção do regime de metas fiscais formais de superávit primário,

\footnotetext{
${ }^{18}$ Esses dados estão citados em Gobetti e Orair (2016); acessamos as fontes graças às indicações fornecidas pelos autores.

${ }^{19}$ Resolução n ${ }^{\circ}$ 9, de 1992. No contexto internacional, essa alíquota pode ser considerada extremamente baixa. EUA e Reino Unido, dois países de tradição de welfare state liberal, têm alíquotas de $40 \%$ gravando heranças (Alvaredo et al., 2017).

${ }^{20}$ Contudo, já nos anos seguintes à promulgação da carta constitucional, como parte da reação conservadora à agenda reformista, parcelas das contribuições sociais foram se desvinculando da seguridade social, “seja pelo não-cumprimento dos dispositivos constitucionais, seja pela retenção dos
} 
as contribuições sociais foram instrumentais para a consecução do ajuste fiscal, que se fez predominantemente por meio da expansão das receitas (Orair et al., 2013). Em ambos os momentos, a despeito dos distintos objetivos, as contribuições sociais foram o principal meio utilizado para elevar as receitas tributárias.

Escrevendo quase três décadas mais tarde, Orair e coautores (Orair et al., 2013) constataram ser realidade aquilo que os pesquisadores da CRETAD haviam previsto - e receado - a respeito das reformas da Constituição de 1988:

As reformas promovidas pela CF/1988 restringiram os recursos disponíveis para a União, via limitação das suas bases tributáveis e ampliação dos montantes de recursos repartidos com os governos subnacionais. $\mathrm{O}$ mecanismo encontrado para equacionar este descompasso e reverter o processo de descentralização tributária foi pelo recurso às contribuições sociais, não compartilhadas com governos subnacionais e vinculadas às despesas de seguridade social, e consequente ampliação da carga tributária [...] As onerações das contribuições sociais mantêm-se como alvo preferencial dos administradores tributários em virtude de suas características extraordinárias - não compartilhadas com estados e municípios, não submetidas aos princípios da anualidade e não cumulatividade e mais facilidades administrativa e de aprovação - e da instituição de instrumentos de desvinculação parcial das suas receitas (Orair et al., 2013, p.36).

Ao fim e ao cabo, ainda que a carga tributária tenha aumentado substancialmente desde 1988, isso pouco se deveu ao imposto de renda - e o sistema tributário foi se tornando sucessivamente mais regressivo ${ }^{21}$. Os temores despertados pela reforma constitucional se revelaram justificados.

\section{CONSIDERAÇÕES FINAIS}

Enquanto em muitos países desenvolvidos a progressividade do sistema tributário esteve presente nas bases da construção de Estados do bem-estar social (Gobetti \& Orair, 2016), no Brasil observamos uma importante inflexão regressiva da arrecadação, promovida justamente pela Constituição de 1988, a mesma que nos aproximou do desenho de um Estado do bem-estar social universalista.

Conforme observamos, a CRETAD, comissão criada pelo governo recém-eleito em 1985, viu suas propostas relativas à equidade serem descaracterizadas ou descartadas. Mais do que isso, além de não promover meios para a necessária ar-

\footnotetext{
recursos no Tesouro Nacional [...]. O resultado é que a União passa a ser financiada pela seguridade e não o contrário, como estabelece a Constituição" (Azeredo, 1990 apud Fagnani, 1997, p.223).

${ }^{21}$ Enquanto a participação do IR, pessoas física e jurídica, na carga tributária passou de $15,5 \%$, em 1990, para 17,3\%, em 2014, o peso das contribuições sociais, excluídas as contribuições previdenciárias, atingiu 27,1\% em 2014, a partir de um patamar de 17,9\% em 1990 (SRF, 1997; CETAD, 2017).
} 
recadação progressiva, a Constituição engendrou mecanismos que, impedindo a ascensão do IR, tornaram a carga tributária cada vez mais regressiva. Aqui há que mencionar a descentralização tributária e a consequente opção preferencial, para o financiamento das despesas da União, pelas regressivas contribuições sociais. Em suma, muito da evolução regressiva de nosso sistema tributário encontra explicação nessas decisões constituintes.

O processo de desconstrução das medidas de equidade sugere implícito pacto social, a hipótese política mencionada ao início: as forças conservadoras que dominaram a transição democrática e se fizeram representar intensamente no processo constituinte consentiram a expansão dos direitos sociais, desde que não tivessem que arcar com a necessária elevação de recursos, no que se empenharam eficazmente. Na verdade, podemos fazer referência a dois pactos, o primeiro, já mencionado; o segundo, apontado por Oliveira $(1987,1992)$, que urdiu alianças em torno a interesses regionais, atenuando divisões com relação à questão distributiva. Interesses poderosos (corporativos e regionais) são mencionados nos documentos analisados como obstáculos ao avanço da progressividade fiscal.

$\mathrm{O}$ argumento da generalidade da Carta Magna aplicado com esmero no debate de justiça fiscal não se mostrou presente em outros contextos e foi falsificado no momento imediatamente pós-constituinte, quando um conjunto de iniciativas fiscalmente regressivas foi disparado por entre as lacunas e barreiras complacentes da Lei maior. Sem entrar em argumentos sobre diferentes tradições constitucionais, o caso brasileiro é interessante porque onde a Constituição marcou como facultativa alguma regra de justiça fiscal (como, por exemplo, a seletividade do ICMS segundo a essencialidade) ela raramente foi seguida, e onde ela foi omissa na exigência de progressividade dos demais impostos, a interpretação do Supremo Tribunal Federal tendeu a ser mais restritiva do que ampla (como no caso da progressividade do IPTU, antes da Emenda Constitucional n ${ }^{\circ} 29$, de 2000, que permitiu a aplicação de alíquotas progressivas em razão do valor do imóvel $)^{22}$. Especificamente no caso do IR, a mera estipulação do princípio da progressividade não foi orientação suficiente para que se estabelecesse posteriormente um grau efetivo de progressividade. $\mathrm{O}$ caso da progressividade no Brasil ilustra o oposto da máxima: "Ça va sans dire".

De modo geral, decisões críticas tomadas durante a constituinte não poderiam ignorar as consequências regressivas das brechas e soluções tributárias finalmente adotadas, alardeadas pelos técnicos envolvidos no processo (ver por exemplo, Varsano, 1987, e Rezende e Afonso, 1987) e por constituintes (como Irajá Rodrigues do PMDB, cf. Finanças, 1988, p.141, e Virgílio Guimarães do PT, Idem, p. 139) aqui incluídas as negociações relativas à descentralização fiscal.

Não nos parece apropriado, contudo, concluir que a reforma tributária da Constituição é a origem exclusiva da regressividade do sistema tributário. A eleva-

\footnotetext{
${ }^{22}$ Para uma análise dos casos, refira-se a Lukic (2017); para a baixa seletividade do ICMS, refira-se a Godoi (2017), que faz discussão detalhada desse aspecto.
} 
da tributação de bens e serviços no Brasil23, que é elemento crucial para explicar esse traço de nosso sistema, precede à CF 1988. Mas a arrecadação do ICMS, em percentual do PIB, aumentou significativamente logo após a Constituição, devido à elevação de sua base de incidência, permanecendo praticamente a mesma, no patamar de $7 \%$ do PIB, desde então, muito em função da guerra fiscal entre os estados da federação ${ }^{24}$. A Constituição não dirigiu a atenção ao problema da ênfase sobre os impostos sobre o consumo. Pelo contrário, ao aumentar sua abrangência, conferir caráter facultativo à seletividade desses tributos (Godoi, 2017) e garantir aos estados e municípios autonomia para fixar alíquotas, tornou pouco provável que haja condições para mudanças convergentes, sobretudo em face da dinâmica de guerras fiscais, ampliadas após 1988 (Rezende, 2009).

Analisar as implicações das medidas tributárias da Constituição nos ajuda a compreender por que tem sido tão difícil levar a cabo a consolidação dos serviços públicos sociais universais e a redução profunda e sustentável das desigualdades por ela almejados - em outras palavras, a economia política da desigualdade.

O modelo regressivo criou armadilhas. Os serviços sociais são deficientes porque subfinanciados e hão de permanecer subfinanciados porque deficientes. Nosso modelo tributário alienou a classe média do usufruto dos bens sociais (de baixa ou incerta qualidade), mas não do pagamento de impostos progressivos como o imposto de renda (é praticamente a classe média que os recolhe), e a empurrou para as hostes da coalizão política regressiva. E, no entanto, a classe média, como ensina a história dos países desenvolvidos, foi ator imprescindível às coalizões que permitiram o desenvolvimento de Estados do bem-estar universalistas (Esping-Andersen, 1990). Por outro lado, a quase inexistente tributação das altas rendas no Brasil é componente central na explicação da concentração no topo e sua resiliência ao longo do tempo, que se deu em simultâneo ao declínio da desigualdade dos rendimentos do trabalho (ver Kerstenetzky, 2017, para análise e referências). Interesses poderosos, antigos e modernos, cuidaram de procrastinar quando não abortar as poucas iniciativas isoladas de reversão do modelo tributário no Brasil democrático.

Por fim, o paradoxo constitucional alerta para os limites de um Estado redistributivo - que efetive direitos sociais e diminua substancialmente a desigualdade - em cujos alicerces não vigore o princípio da solidariedade social.

\footnotetext{
${ }^{23}$ A carga tributária brasileira foi de $33,4 \%$ do PIB em 2014. Impostos sobre renda e propriedade corresponderam a $8,1 \%$, e sobre bens e serviços, a $15,7 \%$ do PIB. A carga tributária de países da OCDE é, em média, de $34 \%$ do PIB, sendo 13,1\% oriundos de renda e propriedade, e 10,5\%, de bens e serviços (Gobetti \& Orair, 2016).

${ }^{24}$ Rezende (2009) constata que, em relação à década de 1980, houve um grande aumento inicial da arrecadação do ICMS, de 5,42\% do PIB, em 1985, para 7,59\%, em 1990, mas logo a participação foi diminuindo, em decorrência do emprego de benefícios fiscais, permanecendo em cerca de 7\% do PIB. O resultado da Constituição, portanto, foi de recolocar o ICMS nos patamares de arrecadação das décadas de 1960 e 1970.
} 


\section{REFERÊNCIAS BIBLIOGRÁFICAS}

AFONSO, José; LOBO, Tereza. Estudos para a Reforma Tributária. Tomo 5: Federalismo Fiscal. IPEA. Textos para discussão interna $\mathrm{n}^{\circ} 108,1987$.

ALVAREDO, Facundo et al. World Inequality Report 2018. World Inequality Lab, 2017.

AZEREDO, Beatriz. Da previdência à Seguridade: Os perigos da transição. Rio Janeiro: UFRJ. IEI, Texto para Discussão n.228, 1990.

BRASIL, Constituição da República Federativa do (1988). Brasília: Senado Federal, 2016.

BRITO, Alessandra; FOGUEL, Miguel; KERSTENETZKY, Celia. The contribution of minimum wage valorization policy to the decline in household income inequality in Brazil: A decomposition approach. Journal of Post Keynesian Economics, vol 40, no 4, 2017.

CASTRO, Lavinia. Esperança, Frustração e Aprendizado: A História da Nova República (1985-1989). In: GIAMBIAGI et al. (Orgs.). Economia Brasileira Contemporânea. Rio de Janeiro: Campus-Elsevier, 2005.

CASTRO, Kléber; AFONSO, José. Gasto social no Brasil pós-1988: Uma análise sob a ótica da descentralização fiscal. Revista de Política, Planejamento e Gestão da Saúde. ABRASCO, vol.1, nº1, pp.34-56, jul-set, 2009.

CETAD Centro de Estudos Tributários e Aduaneiros. Carga Tributária no Brasil 2016: Análise por Tributos e Bases de Incidência. Receita Federal. Brasília, 2017.

DORNELLES, Francisco. A Constituinte e os Impostos. Folha de S. Paulo. São Paulo. Caderno Opinião, p. A3. 31 jul. 1988.

DORNELLES, Francisco. O Sistema Tributário da Constituição de 1988. IN.: Constituição de 1988 - O Brasil 20 Anos Depois, volume IV, pp. 203-244, Brasília: Senado Federal, 2008.

DRAIBE, Sonia. Brasil 1980-2000: Proteção e insegurança sociais em tempos difíceis. Anais do Taller Inter-Regional "Protección Social en una Era Insegura: Un Intercambio Sur-Sur sobre Políticas Sociales Alternativas en Respuesta a la Globalización”, Santiago, maio, 2002.

ESPING-ANDERSEN, Gøsta. The three worlds of welfare capitalism. Princeton: Princeton University Press, 1990.

FAGNANI, Eduardo. Políticas sociais e pactos conservadores no Brasil: 1964-1992. Economia e Sociedade, n. 8, p.183-238, jun. 1997.

FINANÇAS, Comissão do Sistema Tributário, Orçamento e. Atas das reuniões. Abril, 1988. In: FEDERAL, Secretaria Especial de Editoração e Publicações do Senado. Assembleia Nacional Constituinte 20 anos. Brasília: Senado Federal, 2008.

GIFFONI, Francisco; VILLELA, Luiz. Estudos para a Reforma Tributária. Tomo 2: Tributação da renda e patrimônio. IPEA. Textos para Discussão Interna, nº 105, 1987.

GOBETTI, Sérgio; ORAIR, Rodrigo. Progressividade Tributária: A agenda negligenciada. IPEA. Texto para discussão n. 2190, 2016.

GODOI, Marciano. Tributação do Consumo e Efeitos Redistributivos: Alíquotas reduzidas conforme a essencialidade dos produtos/serviços (seletividade) versus alíquotas uniformes com transferências financeiras (refundable tax credits) para famílias de baixa renda. In: AFONSO, José et al. (org.). Tributação e Desigualdade. Belo Horizonte: Letramento: Casa do Direito, 2017.

GOMES, Gerson; CRUZ, Carlos. Vinte Anos de Economia Brasileira - 1995/2014. Brasília: Centro de Altos Estudos Brasil Século XXI, 2015.

GUERREIRO, Maria. Análise dos Gastos Sociais Brasileiros na Perspectiva do Estado de Bem-Estar Social: 1988 a 2008. Dissertação de Mestrado. Programa de Pós-Graduação em Economia da Universidade Federal Fluminense (UFF). Niterói, 2010.

GUTIERREZ, Miguel. O imposto de renda e os princípios da generalidade, da universalidade e da progressividade. Tese de Doutorado. Faculdade de Direito da Universidade de São Paulo (USP), 2009.

HANNI, Michael et al. The redistributive potential of taxation in Latin America. CEPAL Review n. 116, agosto, 2015.

JOUMARD, Isabelle et al. Less Income Inequality and More Growth: Are they compatible? Part 3. Income redistribution via taxes and transfers across OECD countries. OECD Economics Department Working Papers, n 926. Paris: OECD Publishing, Paris, 2012. 
KERSTENETZKY, Celia. O Estado do bem-estar social na idade da razão. Rio de Janeiro: Campus/Elsevier, 2012.

KERSTENETZKY, Celia. Foi um pássaro, foi um avião? Redistribuição no Brasil no século XXI. Novos Estudos CEBRAP. São Paulo, vol. 36, nº 2, pp.15-34, julho, 2017.

LIMA, João et al. A Gênese do Texto da Constituição de 1988. Volume I. Brasília: Senado Federal, 2013.

LUKIC, Melina. Tributação e Equidade Social: Fundamentos constitucionais e precedentes do Supremo Tribunal Federal (STF). In: AFONSO, José et al. (org.). Tributação e Desigualdade. Belo Horizonte: Letramento: Casa do Direito, 2017.

MEDEIROS, Marcelo; SOUZA, Pedro. A estabilidade da desigualdade no Brasil entre 2006 e 2012: Resultados adicionais. Pesquisa \& Planejamento Econômico - PPE, v. 46, n. 3, dez., 2016.

MEDEIROS, Marcelo; SOUZA, Pedro; CASTRO, Fábio. O topo da distribuição de renda no Brasil: Primeiras estimativas com dados tributários e comparação com pesquisas domiciliares (2006-2012). Dados, v. 58, n. 1, pp. 7-36, 2015a.

MEDEIROS, Marcelo; SOUZA, Pedro; CASTRO, Fábio. A estabilidade da desigualdade de renda no Brasil, 2006 a 2012: Estimativa com dados do imposto de renda e pesquisas domiciliares. Ciência \& Saúde Coletiva, v. 20, n. 4, pp. 971-986, 2015b.

MORGAN, Marc. Extreme and Persistent Inequality: New evidence for Brazil Combining National Accounts, Surveys and Fiscal Data, 2001-2015. WID Working Paper Series no 2017/12, 2017.

OLIVEIRA, Fabrício. O Sistema Tributário Brasileiro: Análise crítica da proposta da CRETAD. Revista Administração Pública. Rio de Janeiro, vol. 21, n. 4, pp.116-124, out/dez, 1987.

OLIVEIRA, Fabrício. Crise, Reforma e Desordem do Sistema Tributário Nacional. Tese de Livre Docência. Universidade Estadual de Campinas (UNICAMP). Campinas, 1992.

ORAIR, Rodrigo et al. Carga Tributária Brasileira: Estimação e Análise dos Determinantes da Evolução Recente 2002-2012. IPEA. Texto para Discussão no 1875, 2013.

PILATTI, Adriano. A Constituinte de 1987-1988: Progressistas, conservadores, ordem econômica e regras do jogo. Rio de Janeiro: Lúmen Júris, 2008.

PINHEIRO, Heloisa, WALTENBERG, Fábio, KERSTENETZKY, Celia. et al. Imposto sobre a Renda das Pessoas Físicas: Oportunidades para tributar os rendimentos mais altos no Brasil. In: AFONSO, José et al. (org.). Tributação e Desigualdade. Belo Horizonte: Letramento: Casa do Direito, 2017.

QUEIROZ, Mary. Imposto sobre a renda e proventos de qualquer natureza. Barueri: Editora Manole, 2004.

RAUSCH, Aluizio. O acúmulo intergeracional de riqueza e tributação de heranças e doações no Brasil. Revista Jurídica da Presidência. Brasília, v. 17, n. 113, pp. 547-578, 2015.

REZENDE, Fernando. ICMS: Como era, o que mudou ao longo do tempo, perspectivas e novas mudanças. Cadernos Fórum Fiscal, n. 10, junho, 2009.

REZENDE, Fernando et al. Estudos para a Reforma Tributária. Tomo 1: Proposta de Reforma do Sistema Tributário Brasileiro. IPEA. Textos para discussão interna n. 104, 1987.

REZENDE, Fernando; AFONSO, José. A Reforma Fiscal no Processo de Elaboração da Nova Constituição. IPEA. Textos para discussão interna n. 121, 1987.

REZENDE, Fernando; AZEREDO, Beatriz. Estudos para a Reforma Tributária. Tomo 4: Contribuições Sociais. IPEA. Textos para discussão interna n. 107, 1987.

SOUZA, Celina. Federalismo e Descentralização na Constituição de 1988: Processo decisório, conflitos e alianças. DADOS - Revista de Ciências Sociais, Rio de Janeiro, vol. 44, n. 3, pp. 513-560, 2001.

SRF Secretaria da Receita Federal. Carga Fiscal no Brasil 1996. COGET - Coordenação-Geral de Estudos Econômico-Tributários e Estratégicos. Texto para Discussão, abril, 1997.

VARSANO, Ricardo. Estudos para a Reforma Tributária. Tomo 3: Tributação de Mercadorias e Serviços. IPEA. Textos para discussão interna, n. 106, 1987. 